\title{
The Cattle Grooming Behavior and Some Problems with Technological Grooming Instruments for Cow Welfare
}

\author{
Serap Goncu, Muhammed Ikbal Yesil and Nurten Y1lmaz \\ Animal Science Department, Agriculture Faculty, Cukurova University, Adana 01330, Turkey
}

\begin{abstract}
Thanks to grooming in cattle, dirt, dust and parasites that are removed, skin blood circulation is increased and muscles are massaged. However, grooming should be done with appropriate tools and equipment. Otherwise, it can be more damaging than benefit. There would be a risk that can hurt the animal's life if not paid attention, and may result in injury or even tail rupture. Animals exposed to such situations normally want to escape from grooming and show resistance even though they enjoy it very much. Inaccurate applications during the acclimatization period, the use of small and low-placed brushes that are not suitable for the size and structure of the cattle, malfunctions during the operation of the grooming brush and in the event of incorrect operation, the wounds occurring in different parts of the body can prevent the expected benefit from the use of the grooming brush. But many works carry on this subject to provide more efficient grooming instruments for cow comfort. And grooming is considered a potential indicator of positive welfare. The combination and integration of welfare instruments will ensure optimum wellbeing for dairy animals to maximize profitability. Use of welfare instruments combined with new technologies for information handling and integration to instruments give more effective results.
\end{abstract}

Key words: Cattle, grooming, behavior, technology.

\section{Introduction}

Cattle are herd animals and they feel safe as long as they maintain contact with each other. Grouping is seen during affection, patronage or comfort behaviors. When they perceive danger, animals get closer to each other. As social animals, they usually graze and rest in pairs. Social activities such as coexistence and mutual grooming strengthen group communication. In addition to social effect of grooming, healthy animal appearance can be understood from their clean thin, shiny and elastic skin. Because of these grooming which is natural, indispensable behavior of animals in terms of skin health's protection is very important in daily life. Grooming plays an important role in maintaining the efficiency of the animals at the expected level and in the healthy functioning of their thermoregulatory abilities and in maintaining their health. These creatures do groom by rubbing each

Corresponding author: Serap Goncu, Ph.D., research fields: animal science and cattle husbandry. other or licking each other or themselves with their tongues. Hands and fingertips of humans act as the most sensitive organs in perception, whereas in cattle, mouth, nose and lips serve this function. Grooming is an important behavior in terms of social hierarchy and performance of cows. Grooming behavior is very important for cattle's individual and herd district. If cattle cannot find grooming possibilities they showed abnormal behavior [1].

Self-grooming will often make use of environmental items in extensive production systems, to scratch on, such as boughs, brushes, trees, fences and posts, particularly for areas of the body inaccessible to the mouth, tongue and feet [2]. This behavior involves licking by tongue, scratching with their hind feet, scratching with their horns, and swatting with the tail in an effort to clean all areas of their bodies that they can reach [2]. To reach inaccessible parts, such as the head, neck, back, and hind quarters, cattle will often scratch themselves on inanimate objects. Georg and Totschek [3] reported 
that the frustration or stress occur due to boredom in intensive housing systems.

Grooming each other is a common behavior which is generally done according to the hierarchy within the flock. Grooming is a process in which many animals apply to each other to clean their bodies, skins and furs. Grooming starts with the head, continues with the back and sides and ends with the bottom of the tail. Grooming also means cleaning, stimulating capillaries, skin care and parasite control. The purpose of grooming is to remove vestigial hair and dead-cells of skin. All parts of the body can be reached by the tongue with a little pressure, licking behavior and grooming is done. They scratch their heads, ears and upper neck areas by using their hind legs and their back of the body by using objects such as trees or fences. Although the animals groom themselves on their own, there is also mutual grooming from time to time. This grooming form contributes to mutual communication and is usually initiated by cattle that are lower in the hierarchical order. The cattle stand side by side with one's nose on the other's tail and grooming areas that are not accessible to each other.

Cows are reported to be grooming themselves for at least 3 times a day and 1-1.5 minutes each time when a barn brush is installed. And the interesting point is that when the grooming brush was first put in the compartment, half of the cows in the herd came and tried it, although it was a new practice [2]. The research also shows the highest groomed body area with $11 \%$ of grooming cows' necks, $3 \%$ of thighs and $86 \%$ of head. In addition, cattle use the brushes to soothe by scratching their neck and the ears' back, which are sensitive to touch by using the brush [4]. Mandel, et al. [5] reported that the frequency of brush use decreases in case of stressful situations. It can be accepted that increased brush use may be indicator of positive emotional status of cows. Keeling, et al. [6] reported that each additional time the cow used the brush is associated with $0.75 \mathrm{~kg}$ higher milk yield per day ( $p<$ 0.01 ) and with $0.32 \mathrm{~kg}$ more dry matter consumed per day $(p<0.001)$. But brush usage decreased when cow was subjected to medical procedures [5]. Location of the brushes is also important to effective brush usage. Also barn temperature and humidity levels are effective to brush usage. Breed, lactation number, stage of lactation, dominance or affiliative rank of the cows are effective to brush usage rate.

Animals lick by their tongue and use saliva as secretion during grooming. Saliva is a special fluid produced by the salivary glands under the tongue in the mouth of the animal [6]. Salivary secretion contains many substances that provide digestion in the rumen and reduce the acidity in the rumen [7-11]. If digestive disorders occur the animal ruminates less and thereby reduce salivation. Microorganisms found in rumen which are beneficial for the digestion of the animal are damaged. There are two main factors that prevent relaxation and, consequently, salivation [11]. One is the ratio of roughage and the other is concentrate in total daily feed. The ratio of roughage in the total daily feed should be around $50 \%$. However, the rate of roughage in very high yielding animals can be allowed to decrease up to $40 \%$. Roughage rate should never be less than $40 \%$ in dairy cattle. Rough ration is reduced in underfed cattle in terms of roughage. The other is the chopping length of roughage. Very fine chopped straw, corn silage, such as roughage, as well as the structural fiber-poor fresh green tea grass and beet, tomato and apple pulp ruminant preventive effect. Therefore, such roughage must be mixed with hay or coarsely chopped hay. Feeding the feeds by wetting or slurring also reduces the salivation. The esophagus is a little shorter than 1 $\mathrm{m}$ and provides the passage of the feed mixed with saliva in the mouth to the rumen. Apart from these, it has no digestive activity.

A cow that consumes an average of $18.2 \mathrm{~kg}$ dry matter and produces 10 to $32 \mathrm{~L}$ saliva per $\mathrm{kg}$ of dry matter. Saliva quantity varies according to feed consumption and feed content [11]. Cattle have a large number of glands located around the mouth. Of these, 
saliva is secreted with little difference between their compositions. Salivation is important in feeding cows. A cow with a good nutritional program releases about 180 L of saliva per day. The maximum salivation occurs during ruminating. An animal rises secretes $160 \mathrm{~mL}$ of saliva per minute. The saliva $\mathrm{pH}$ is 8.2 . Rumen $\mathrm{pH}$ is between 5.8-6.2 [12].

Saliva with a mean $\mathrm{pH}$ of 8.2 and high sodium bicarbonate has a buffering effect in rumen. This means that saliva helps counteract the effects of acid-producing feedstuffs such as cereals, molasses, potatoes and fodder beets on rumen acidity level. In addition, saliva suppresses the foam in the rumen. It reduces the risk of swelling of saliva because it has foam suppression effect in rumen.

Saliva is a fluid that causes digestion to begin. Saliva, which breaks down starch to maltose and dextrin, facilitates digestion at other stages. Again, saliva destroys many possible bacteria in the mouth. However, the effect of these antibacterial compounds is insufficient unless regular cleaning of the mouth is provided. In addition, saliva breaks down tartars that remain in the mouth, sticks to the teeth and continues to decompose any feed residues that remain in the mouth. Some animals, such as snakes, also produce poison in their saliva-like organs to protect themselves from enemies.

\section{Grooming Effect}

Regular grooming improves cattle appearance, increases blood circulation, and stimulates skin, which make the cattle coat shiny. Fraser and Broom [12] reported the dopaminergic functions to all grooming. Researcher reported that the hormone prolactin is associated with grooming and has dopaminergic activity so grooming causes opiate induction and self-narcotization using prolactin way. Keeling, et al. [6] reported that time budget for cows was $42 \%$ lying, $27 \%$ walking or standing, $16 \%$ feeding, $10 \%$ queuing to be milked and $1 \%$ of their time drinking, using the brush or being milked. Cattle with access to mechanical brushes are cleaner and spend about fivefold more time grooming compared with when brushes are not available. Perhaps very little time schedules for grooming. Grooming is also a good opportunity for checking animal body for injuries, skin irritations or other health problems. Continuous cattle grooming will build trust and confidence between cattle and handler. Farmers develop a positive relationship with cattle during grooming. Grooming allows cows to bond with their herd mates and reduces the impact of the boss cow/submissive cow hierarchy within the herd. Cows also use grooming as a way to cope with stressful situations. But grooming effect is relatively important. The decrease in brush use might therefore occur before a decrease in milk production or an increase in sub-clinical signs [6]. When provided, 85 to 100 percent of cows in a herd used brush daily. And brushes improve cows' scratching time by six times. Milk production is also improved. Some researchers reported that the milk production is improved as a result of increased cow activity to use brushes and active cows utilize ketones more effectively on body reserve. Brush usage can also improve animal cleanliness. This could improve animal udder health and decrease mastitis risk.

After grooming, the skin on the salt, sweat, organic substances, such as eggs which is left by the flies and the external parasites are cleaned. Grooming is the behavioral characteristics of cows that promote health, calmness, well-being and overall performance. Grooming has a positive effect on animals, the formation of herd instinct, calm down of animals, prevention of skin diseases, cleaning of the skin; the blood flow in the skin is stimulated, prevents stress, increases animal welfare, the skin gets a healthier appearance, the stimulation of the nerves in the skin is easy to apply [14]. The overall objective of grooming cattle is to give them the best overall conformation. It is also known to increase milk yield by $10 \%-14 \%$. The differences in the values of per day milk yield as 
influenced by different treatments of bathing and grooming combinations in cross-bred cows during summer season are significant reported by Pandey and Neeraj [14]. Researcher reported that the cows groomed thrice and given bath twice a day give more milk 7,480 $\mathrm{kg}$ during the summer season and $5,513 \mathrm{~kg}$ for rainy season. Verma, et al. [15] reported that two times bathing and grooming in cross-bred cows under hot conditions may be used as effective routine managemental practices to obtain higher milk yield and its compositional quality as well as reduce heat stress during summer season. Researcher also reported that bathing and grooming were effective for increasing the fat percent in milk of crossbred cows. The cattle grooming improves feed intake up to a 3.5\% rise in milk production. Schukken and Young [16] reported that the mechanical rotating brushes resulted in a significant increase in milk production of cows and a significant decrease in clinical mastitis.

Some country grooming brushes are mandatory for intensive dairy farms to provide comfortable environment. There are many types of grooming equipment on the market. Some of these tools are made of pliable plastic, some of them metallic while other wooden. Basic grooming tools are a comb, brush, scraper and grooming cloth. Cattle show big variation aspect of response grooming equipment. Some of them have greater sensitivity than others to grooming. Also, disinfection and care of grooming tools is very important and the use of tools from outside the farm increases the risk of disease. Also, necessary safety precautions should be taken when working with animals, because many activities contain risk such as leaning over to hooves, stooping to check legs, moving hay bales, repetitive motions in brushing and grooming, reaching above the head for grooming, tacking, etc. The grooming environment must be organized for safety.

\section{Manual Grooming}

In natural environments, cattle use trees and other abrasive surfaces to scratch and groom themselves.
Modern indoor dairy cattle housing systems often lack appropriate grooming substrates, restricting the animals' ability to groom. The first time to work with a grooming cow waiting for the animal to approach the gently touching of the body of the neck is to groom. In the lapping process, grooming the neck and half of the body is more than sufficient. Touching the feet to grooming can cause the animal during the adaptation phase. Grooming the animal 2-3 times is enough to get rid of this type of negative response. The pressure that can be applied in the use of brushes and bowls depends on the animal's body area, skin thickness and brush characteristics. Before starting grooming, brush all over the cattle with a hard brush. However, hard brush should not be used in the compression and bony areas of the shallow. Dust and hairs are removed from the bowl with a soft brush. Grooming is completed by wiping with the last genre or towel.

If a cow cannot find cows to groom, they will approach the walls, pipes, timber or similar materials in the shelter and try to groom themselves with them. The skin is equipped with various receptors. There are receptors to detect movement in the skin, detrimental effects, hot or cold and pathological conditions. Lip, tongue, nipple and vulva are the most sensitive areas in cattle.

All cattle age groups, whether pastures or cows in the barn, want to relax and scratch themselves and use the many materials around them for this purpose. Friction on fence posts, sharp metal corners, scratching with rusty nails in buildings can cause negative effects such as opening, irritation, hair loss, scars and irritations on animals' skins. There are many materials developed against these negative effects. Itching pads, grooming brushes are the best examples. Animals should be groomed from time to time with the help of materials such as spoon, brush, sponge, comb and cloth.

For this reason, in recent years, many companies have developed brushes for grooming systems to 
relieve animals and make them available to farms. These brushes are mounted in a stable place with a suitable height and inclination in the barn, and the cow comes to the side of the brush and gently starts to rotate when he starts rubbing his back with his head. Dairy cattle breeders state that cows use these brushes to make them cleaner, calmer and more comfortable. As the brushes are cow-cleansing, they also reduce the risk of disease associated with barn dirt such as mastitis.

Manual grooming is a time-consuming and labor-intensive task. In addition, the risk of occupational safety is high for inexperienced people. For this reason, mechanical grooming bases have been developed.

\section{Mechanical Grooming}

Intensive dairy farms provide automated mechanical brushes to provide grooming behavior. Mechanical grooming brushes have many different types for different purposes. Some types of these mechanical brushes contain massage fluids which protect cattle skin health and protect against some parasites. It is designed to be protected against dust and water as it will be used in the barn. The brush is made of long-lasting plastic with softness that will not irritate or injure the animal. The system comprises an L-shaped adjustable support frame for wall or pole mounting, a support spring between the frame, a vertical brush contacting the animal, and an electric motor.

The brush will be mounted in a suitable place in the barn, and when the animal comes to contact the brush itself, the brush will start to rotate slowly, smoothly and comfortably and work in such a way that it can move around the cow or in response to the animal moving the device upwards. The engine of the nail brush will run quietly so that there is no disturbance on the animals. Designed for cattle grooming, this brush system includes a movable motor mounted on a fixed support structure and the motor moves with the brush during operation of the device. The motor is placed vertically on the brush.

Generally, the grooming brush length is maximum $75 \mathrm{~cm}$ and it can brush up to the head, neck and body of the animal. This causes deficiencies in the lower parts of the thigh and the lower parts of the abdomen. It may also be caused by problems such as contact or tail fitting to the heat detection pads. But this grooming equipment has been developed for cows to scratch themselves depending on their requirements.

These types of brushes are also proven for beef farm. Similarly, this brush keeps bulls clean and healthy by removing dirt and other parasites, while improving barn hygiene at the same time. All these brushes maintain the optimum massage effect on cow. All these types of brushes are developed for best pressure on the skin to stimulate blood circulation for best performances.

\subsection{Stationary Brushes}

Stationary brushes consist of a horizontal brush and a vertical brush. Some models have a specific pattern to be adjustable on the size of the cow, which allows the use of cows of different sizes within the herd.

\subsection{Rotating Brushes}

Rotating cow brushes have a brush that rotates on a horizontal arm attached to a motor which swings left and right $\left(45^{\circ}\right)$. Rotation is activated when the cows move the brush and continue until the arm remains horizontal for a period of time. The rotating cow brush, which can be easily attached to wall or support, starts immediately when touched by a cow. It is driven by a $250 \mathrm{~W}$ electric motor, controlled by micro processors. Additionally, it stops automatically in a few seconds after a cow walks away. It immediately stops turning if something gets caught in the brush and reverses direction.

\subsection{Swinging Brushes}

Swinging brush swings freely in all directions, smoothly up, over and alongside the cow. The rotating 
starts when the cow pushes the brush and continues to rotate until it remains vertical for a period of time.

\section{Assessment of Brush Usage Level at Farms}

The rate of use of brushes of cows in the barn provides some important information on disease, suboptimal microclimate and social problems in herd. On a herd level, brush use could be an indicator of the general welfare and used as a benchmark between herds $[5,6]$. The behavioral time budget for cows was $42 \%$ lying, $27 \%$ walking or standing, $16 \%$ feeding, $10 \%$ queuing to be milked and $1 \%$ of their time drinking, using the brush or being milked [6]. But many factors have effect on brush usage at farm level. Brush usage is affected by overstocking in the barn level. General recommendation is 50 to 60 cows per brush. Breed, lactation number, stage of lactation, dominance or affiliative rank of the cows are effective to brush usage rate. But location of brush, stress level, barn microclimate, and herd social status can be main factor. Because the cow brush usage rate can demonstrate animal welfare, this might give an indication of a change to microclimate of animals that would be difficult to identify by other measures. But still some problems remain at brushes usage at farm level and need more detailed experiments for better performances.

\section{Conclusions}

It can be said that limited research results published on the grooming brushes usage and the results so far have been positive. When provided, 85 to 100 percent of cows in a herd used brush daily. And brushes improve cows scratching time by six times. And milk production is also improved. Three types of brushes are available on the market which have different size, type and price. These are stationary, rotating and swinging brushes. Many of them are similar to each other but the some of them have more range of motion, allowing it to swing back, forth, and side to side.
Overcrowding around the brushes and social dominance issues are very big stress for subordinate cow brush usage rate. Tail chalk (for heat detection) can be rubbed off, and rump-mounted heat-detection devices may be inadvertently activated. The use of a mechanical brush influenced behavior, reducing not active time, while increasing eating time. The consequences of this change in activity require further investigation for better performances and welfare criteria.

\section{References}

[1] Ewing, S. A., Lay, D. C., and Von Borell, E. 1999. Farm Animal Well Being. Upper Saddle River, NJ: Prentice Hall.

[2] DeVries, J. J., Vankova, M., Veira, D. M., and von Keyserlingk, M. A. G. 2007. "Short Communication: Usage of Mechanical Brushes by Lactating Dairy Cows." T. Dairy Sci. 90: 2241-5. doi:10.3168/jds.2006-648.

[3] Georg, H., and Totschek, K. 2001. "Examining an Automatic Cow brush for Dairy Cows." Landtechnik 56: 260-1.

[4] Moran, J. 1993. Calf Rearing-A Guide to Rearing Calves in Australia. Victoria, Australia: Agmedia/Dept. of Agriculture.

[5] Mandel, R., Whay, H. R., Nicol, C. J., and Klement, E. 2013. "The Effect of Food Location, Heat Load, and Intrusive Medical Procedures on Brushing Activity in Dairy Cows.” Journal of Dairy Science 96: 6506-13.

[6] Keeling, L. J., De Oliveira D., and Rustas, B. O. 2019. "Positive Relationships between Use of Mechanical Rotating Brushes, Social Behavior and Production Parameters in Loose-Housed Dairy Cows." Accessed on October 1, 2019. http://www.dairycareaction. org/uploads/2/4/2/6/24266896/keeling_parallel.pdf.

[7] Reid, J. T., and Huffman C. F. 1949. "Some Physical and Chemical Properties of Bovine Saliva Which May Affect Rumen Digestion and Synthesis." Journal of Dairy Science 32 (2): 123-32.

[8] Levine, M. J. 1993. "Salivary Macromolecules: Structure/Function Synopsis." Ann. NY Acad. Sci. 694: $11-6$.

[9] Maekawa, M., Beauchemin, K. A., and Christensen, D. A. 2002. "Chewing Activity, Saliva Production, and Ruminal pH of Primiparous and Multiparous Lactating Dairy Cows.” J. Dairy Sci. 85 (5): 1176-8.

[10] Lopatine, D. 2017. "Chemical Composition and Functions of Saliva." Accessed on April 7, 2017. www. umich.edu/.../salivarygland/.../Chem_Comp_\&_Func. 
[11] Yousef, R. T., and Tawil, G. G. 1980. "Antimicrobial Activity of Volatile Oils." Pharmazia 35: 698-701.

[12] Fraser, A. F., and Broom, D. M. 1990. Farm Animal Behaviour and Welfare. London: Baillière Tindall.

[13] Uygur, F. 2016. Genel Hayvan Yetiştirme. https://cdn.comu.edu.tr/cms/ziraat.zootekni/files/4-hayva n-yetistirme.pdf.

[14] Pandey, R., and Neeraj. 2014. "Influence of Different Bathing and Grooming Combinations on Productive Performance of Cross-Bred Cows." Journal of
International Academic Research For Multidisciplinary 2 (10): 213-7.

[15] Verma, D., Singh, S., Shukla, A., Pandey, R., Pankaj, N., Singh, K., et al. 2017. "Effect of Grooming and Bathing on Milk Yield and Milk Composition in Crossbred Cows during Summer Season.” Journal of Pharmacognosy and Phytochemistry 6 (1): 987-9.

[16] Schukken, Y. H., and Young, G. D. 2010. "Effects of Swinging Cow Brush on Milk Production and Mastitis." Western Dairy News 10 (5): 87-8. 